\title{
Novel regulatory roles of omega-3 fatty acids in metabolic pathways: a proteomics approach
}

\author{
Abeer A Ahmed ${ }^{1}$, Kayode A Balogun ${ }^{1}$, Natalia V Bykova ${ }^{2,3}$ and Sukhinder K Cheema ${ }^{1 *}$
}

\begin{abstract}
Background: Omega-3 polyunsaturated fatty acids ( $n-3$ PUFA) have been shown to alleviate the symptoms of metabolic disorders, such as heart disease, diabetes, obesity and insulin resistance. Several putative mechanisms by which n-3 PUFA elicit beneficial health effects have been proposed; however, there is still a shortage of knowledge on the proteins and pathways that are regulated by $n-3$ PUFA.

Methods: Using two dimensional polyacrylamide gel electrophoresis (2D-PAGE) and liquid chromatography-tandem mass spectrometry (LC-MS/MS) analysis, we investigated the effects of diets high or low in n-3 PUFA on hepatic proteomic profile of C57BL/6 mice.

Results: The findings show for the first time that high dietary n-3 PUFA reduced the expression of regucalcin, adenosine kinase and aldehyde dehydrogenase. On the other hand, diets high in $n$-3 PUFA increased the expression of apolipoprotein A-I, S-adenosylmethionine synthase, fructose-1, 6-bisphosphatase, ketohexokinase, malate dehydrogenase, GTP-specific succinyl CoA synthase, ornithine aminotransferase and protein disulfide isomerase-A3.

Conclusions: Our findings revealed for the first time that $n-3$ PUFA causes alterations in several novel functional proteins involved in regulating lipid, carbohydrate, one-carbon, citric acid cycle and protein metabolism, suggesting integrated regulation of metabolic pathways. These novel proteins are potential targets to develop therapeutic strategies against metabolic disorders.
\end{abstract}

\section{Background}

Nutrients have the ability to interact and modulate molecular mechanisms responsible for an organism's physiological functions [1]. Over the past decades, the importance of nutrients, especially omega (n)-3 polyunsaturated fatty acids (PUFA), in the aetiology of chronic diseases has gained a lot of attention [2-4]. N-3 PUFA have been shown to be beneficial in a variety of disease conditions such as, atherosclerosis [5], obesity [6], and obesity induced insulin resistance in liver $[7,8]$. The cardio-protective effects of $n-3$ PUFA are the most characterized; $n$-3 PUFA improve cardiovascular health mainly by reducing plasma triglyceride (TG) levels [9], resolving the symptoms of arrhythmia [10] and inflammation [11]. The $n$-3 PUFA cardio-protective effect depends mainly on its dosage [12-14]. The American Heart Association has recommended 1,000 mg/d for treatment of

\footnotetext{
*Correspondence: skaur@mun.ca

'Department of Biochemistry, Memorial University of Newfoundland, St. John's, NL, A1B 3X9, Canada

Full list of author information is available at the end of the article
}

existing cardiovascular diseases (CVDs) [15]. Studies have also shown that $n-3$ PUFA stimulate muscle glycogen synthesis [16] and modulate antioxidant enzyme activity, such as superoxide dismutase and catalase in livers from diabetic rats fed a high fat diet [17]. Conversely, diets high in $n-6$ PUFA are considered to increase the risk of inflammatory [18] and oxidative stress pathways [19], which are confounding factors of most metabolic diseases. Several mechanisms have been proposed by which $n-3$ and $n-6$ PUFA exert their biological actions $[20,21]$, however, the information available is scanty, inconclusive, and does not explicitly define the proteins and pathways involved in the actions of PUFA.

$N-3$ and $n-6$ PUFA form bioactive mediators which act on different receptors and proteins in the body [22]. Proteins are important mediators of biological activities in all living cellular units, and the proteome is comprised of all expressed proteins encoded by the genome of a cellular system [23]. The analysis of nutrient mediated changes in the proteomic profile can lead to identification of novel 
proteins involved in the regulation of metabolic pathways [24]. In the current study, we used 2D-PAGE coupled with LC-MS/MS to investigate the effect of $n-3$ PUFA on the regulation of hepatic proteomic profile of $\mathrm{C} 57 \mathrm{BL} / 6$ mice. Our findings show for the first time that dietary $n-3$ PUFA reduced the expression of regucalcin, a key molecule involved in metabolic disorders including diabetes and lipid metabolism. We also report for the first time that $n-3$ PUFA regulate several proteins involved in the regulation of lipid metabolism, one-carbon metabolism, carbohydrate, citric acid cycle, and protein synthesis.

\section{Methods}

\section{Diet and animals}

A base semi-synthetic diet designed specifically to permit the control of fat level at $20 \% \mathrm{w} / \mathrm{w}$ was obtained in powdered form with the fat source omitted (MP Biomedicals, $\mathrm{OH}, \mathrm{USA}$ ). Menhaden oil (Sigma-Aldrich, MO, USA); lard, safflower oil and extra-virgin olive oil were used to prepare two different oil mixtures containing 10\% (high $n-3)$ and $2 \%$ (low $n-3) n-3$ PUFA of the total fat and has been previously published [25]. The amount of saturated fatty acids (SFA), monounsaturated fatty acids (MUFA) and total PUFA was kept constant. The two experimental diets differed only in the $n-3$ PUFA amount; the high $n-3$ PUFA diet contains $10 \% n-3$ PUFA while the low $n-3$ PUFA diet contains $2 \% n-3$ PUFA of the total dietary fat. Gas-liquid chromatography (GLC) was used to determine the fatty acid composition of the diet, which has been previously published [25]. Seven weeks old C57BL/6 mice were purchased from Charles River Laboratories (MA, USA). Animals were housed in a temperature-controlled animal facility with a $12 \mathrm{~h}$ light-dark cycle. The mice were maintained for one week acclimatization period on a regular chow diet (Prolab RMH 3000) purchased from PMI nutrition (MO, USA). Female mice were placed on one of the two experimental diets (low or high $n$ - 3 PUFA diets) for 2 weeks prior to mating, and they continued on designated diets through gestation, lactation, and until weaning. At weaning, male and female offspring were continued on their mothers' diets for four months. Animals were provided with water and fresh diet ad libitum, every other day. Body weights were recorded once a week, and diet intake was recorded every other day. No significant differences were observed in both body weight and diet intake (Data not shown). At the end of the experimental period, animals $(n=4)$ were fasted overnight and blood was collected by cardiac puncture in tubes containing EDTA (4.5 mM, pH 7.4) to separate plasma. Livers were immediately snap frozen in liquid nitrogen and stored at $-80^{\circ} \mathrm{C}$ until further use. Institutional Animal Care Committee at Memorial University approved all experiments in compliance with the guidelines of the Canadian Council for Animal Care.

\section{Lipids and glucose analysis}

Hepatic lipids were extracted according to our previously published method [26], and analyzed for TG concentrations using a TG assay kit (\# 236-60, Sekisui Diagnostics, P.E.I Inc., Canada). Plasma samples were used for determination of non-esterified fatty acids (NEFA) using a kit (\# 993-35191, Wako Chemicals Inc., USA). Fasting blood glucose concentrations were measured at the time of sacrifice using a commercially available glucometer (Lifescan Inc. CA, USA) after snipping the tail.

\section{Ornithine aminotransferase (OAT) activity analysis}

Hepatic OAT activity was assayed according to the method of Herzfeld and Knox [27] and protein concentration of liver extract was determined using the Biuret method [28]. The OAT enzyme activity was standardized for linearity with time, protein concentration, and was expressed as $\mu \mathrm{mol} / \mathrm{min} / \mathrm{g}$ liver.

\section{Proteomic profiling}

Liver samples ( $\mathrm{n}=4$ per treatment group) (30 mg each) were homogenized in $40 \mathrm{mM}$ Tris to profile the hydrophilic proteome soluble in aqueous buffer. Separation of the supernatant was performed after centrifugation (3000 rpm for 3 minutes at $4^{\circ} \mathrm{C}$ ). Protein concentration was assayed by the method of Bradford [29]. An aliquot of $800 \mu \mathrm{g}$ total protein was added to $10 \mathrm{ml}$ pre-chilled $85 \%$ acetone $/ 0.07 \%$ dithiothreitol (DTT) at $-20^{\circ} \mathrm{C}$ for a final concentration of $80 \%$ acetone; washing and centrifugation steps were repeated six times to remove all the water soluble contaminants, and the pure protein pellet was dried under nitrogen gas. Washing with several acetone precipitation rounds improves the quality of Isoelectric focusing (IEF) significantly [30]. The purified protein sample was suspended directly into rehydration buffer (7.0 M urea, 2.0 M thiourea, 4\% CHAPS, $30 \mathrm{mM}$ DTT, 1\% Bio-Rad 3-10 ampholyte, bromophenol blue) to a final volume of $500 \mu \mathrm{L}$ per sample, and centrifuged at $100,000 \times \mathrm{g}$ for $30 \mathrm{~min}$ prior to overnight loading via rehydration of immobilized $\mathrm{pH}$ gradient (IPG) strips. IEF was conducted with the Ettan IPGphor II system and Manifold tray (GE Healthcare, Piscataway, NJ, USA) using $24 \mathrm{~cm}$ ReadyStrip IPG (Bio-Rad, Mississauga, Ontario Cat. No.163-2042). The strips were focused for a total of 100 $\mathrm{kVh}$ prior to running the second dimension gels. The IPG strips were incubated for $10 \mathrm{~min}$ in equilibrium buffer (1.5 M Tris- $\mathrm{HCl}, \mathrm{pH} 8.8$, sodium dodecyl sulfate (SDS), urea, glycerol, bromophenol blue) with 1\% DTT followed by $10 \mathrm{~min}$ in the same buffer containing $2.5 \%$ iodoacetamide. The second-dimension Tris-glycine SDS-PAGE was carried out using $20 \mathrm{~cm}$ gradient $10-20 \%$ acrylamide gels as described elsewhere using an Ettan DALT six (GE Healthcare) apparatus [31]. The total protein content was 
detected by staining overnight with $0.15 \% \mathrm{w} / \mathrm{v}$ Coomassie blue R250; destained for $1 \mathrm{~h}$ with $25 \% \mathrm{v} / \mathrm{v}$ ethanol, $7 \% \mathrm{v} / \mathrm{v}$ acetic acid.

\section{Protein quantification and identification using progenesis gel imaging}

The images of the total protein pattern of 2D-gels were captured by video imaging using the ImageScanner III (LabScan 6.0 software, GE Healthcare, Life Sciences, Sweden). We then used a specialized software, Progenesis Samespots, version 3.1 (Non-linear Dynamics, Newcastle upon Tyne, UK) to align and quantify the protein spots from captured 2D-gel images. The use of identical spot boundaries across all gels, background subtraction, and normalization to total staining intensity in each gel ensured comparable data between all gels with the Progenesis Samespots software. Each spot was manually evaluated using a 3D image display to exclude artifacts (spiky or irregularly shaped spots, split spots etc.). For the identified real spots, image realigning, noise filtering, and spots segmentation were carried out using default setting [32]. Automatic analysis was performed on all the aligned images using the analysis wizard. The aligned images were grouped into high and low $n-3$ PUFA group, and the statistically ranked list of spots was evaluated.

\section{In-gel digestion and peptide extraction}

Excised protein spots in 1.5 siliconised polypropylene vials were washed 3 times with $100 \mathrm{mM}$ ammonium bicarbonate/acetonitrile $\left(\mathrm{NH}_{4} \mathrm{HCO}_{3} / \mathrm{ACN}\right)$ and proteins were reduced with $10 \mathrm{mM}$ DTT in $100 \mathrm{mM} \mathrm{NH}_{4} \mathrm{HCO}_{3}$ for $30 \mathrm{~min}$ at $56^{\circ} \mathrm{C}$ [33]. After cooling to room temperature, excess DTT solution was removed, and samples were alkylated with $55 \mathrm{mM}$ iodoacetamide in $100 \mathrm{mM} \mathrm{NH} \mathrm{mCO}_{3}$ for $30 \mathrm{~min}$ at room temperature in the dark. Excess iodoacetamide solution was removed, and gel pieces were washed again with $100 \mathrm{mM} \mathrm{NH} \mathrm{HCO}_{3} / \mathrm{ACN}, 1: 1 \mathrm{v} / \mathrm{v}$. The samples were dehydrated for $20 \mathrm{~min}$ with $\mathrm{ACN}$, and subsequently rehydrated with $12.5 \mathrm{ng} / \mu \mathrm{l}$ sequencing grade modified Trypsin buffer (100 mM NH $\mathrm{mCO}_{3}, 10 \% \mathrm{ACN}$, $2.5 \mathrm{mM} \mathrm{CaCl}_{2}$ ) for 30-40 min on ice [34]. Samples were incubated at $37^{\circ} \mathrm{C}$ overnight. After cooling to room temperature, $50 \mu \mathrm{l}$ of $5 \%$ formic acid (FA) was added, samples were vortexed and centrifuged at $6000 \mathrm{rpm}$ for $2 \mathrm{~min}$, and the clear supernatant was collected into fresh siliconised tubes. The extraction process was repeated using $1 \%$ FA, 5\% ACN; 1\% FA, 60\% ACN; 1\% FA and 99\% ACN. The combined extracts were dried under vacuum.

\section{Mass spectrometric analysis of peptide extracts and database searching}

For peptide mapping and fragmentation analysis with matrix assisted laser desorption/ionization time-of-flight mass spectrometry (MALDI TOF MS), each concentrated peptide extract was purified with a $\mu \mathrm{C} 18$-Ziptip (Millipore, Billerica, MA) pipette tip. The bound peptides in the ZipTip were eluted using the elution solution (50\% ACN in 5\% FA, 2,5-Dihydroxybenzoic acid (DHB $10 \mathrm{mg} / 67 \mu \mathrm{L}$ ). For sample spotting, we used the dried droplet method [35]. $4 \mu \mathrm{L}$ sample was deposited on the target into two spots with $2 \mu \mathrm{L}$ each. Calibration was done first externally to obtain 10-20 ppm accuracy with known peptide standards. Internal calibration was performed with known matrix cluster signals and tryptic autolysis peptide signals to achieve a mass accuracy of less than $100 \mathrm{ppm}$. Single MS with $\mathrm{m} / \mathrm{z}$ range $600-3000$, and MS/MS analysis was conducted using the QSTAR XL hybrid quadrupole/time of flight mass spectrometer equipped with an o-MALDI ion source (Applied Biosystems, Foster City, CA) located at Memorial University Genomics and Proteomics (GaP) facility. The instrument exhibits a mass resolving power of 10000 full-width half-maximum, and accuracy within a few millidaltons in the TOF spectra in both MS and MS/ MS modes. A peak list was created with the Applied Biosystems Data Explorer from the unsmoothed raw data spectrum after de-isotoping. Monoisotopic $\mathrm{m} / \mathrm{z}$ values from known matrix-cluster peaks and signals from trypsin autolysis peptides or known peptides derived from keratins [36] were manually removed from this list before it was copied to the query section of the MASCOT Peptide Mass Fingerprint online entry form at www.matrixscience.com [37]. The following settings were applied for the online database search: Database = NCBInr $20111022(15670863$ sequences; 5387755057 residues); Taxonomy = Musculus; Enzyme $=$ Trypsin (with a maximum of 2 missed cleavages); Fixed modifications $=$ Carbamidomethyl $(\mathrm{C})$; Variable modifications $=$ Acetyl $($ Protein N-term) and Oxidation (M); Peptide tolerance $= \pm 100 \mathrm{ppm}$; Mass values $=\mathrm{MH}+($ monoisotopic). Only probability scores, $\mathrm{p}<0.05$, were considered.

\section{Protein identification using liquid chromatography- tandem mass spectrometry}

Separation of peptide mixture was conducted using a DIONEX UltiMate 3000 Nano LC System (Germering, Germany). Protein digest (250 fmol) was loaded onto a C18 pre-column (LC Packing, Sunnyvale, CA) for desalting and concentrating. Peptides were then eluted from the pre-column and separated on a nano-flow analytical C18 column (PepMap $75 \mu \mathrm{m}$ i. d., LC Packing, Sunnyvale, $\mathrm{CA})$ at $180 \mathrm{nl} / \mathrm{min}$ using an $\mathrm{ACN}$ gradient. The mobile phase consisted of (A) $0.1 \%$ FA/0.01\% trifluoroacetic acid (TFA) $/ 2 \%$ ACN and (B) 0.08\% FA/0.008\% TFA/98\% ACN. A gradient of $0 \% \mathrm{~B}$ for $10 \mathrm{~min}, 0-60 \% \mathrm{~B}$ for $55 \mathrm{~min}$, $60-90 \%$ for $3 \mathrm{~min}, 90 \%$ B for $5 \mathrm{~min}$ was applied. An Applied Biosystems QSTAR XL (Applied Biosystems/MDS Sciex, Foster City, USA) hybrid quadrupole TOF-MS/ MS system equipped with a nanoelectrospray source (Protana XYZ manipulator) located at Memorial University 
Genomics and Proteomics (GaP) facility was used for LC-MS/MS peptide sequence analysis. The nanoelectrospray was generated from a PicoTip needle $(10 \mu \mathrm{m}$ i.d., New Objectives, Wobum, USA) at a voltage of $2400 \mathrm{~V}$. Information-dependent acquisition in positive ion mode was employed with one MS m/z range of 400-1500 and $\mathrm{MS} / \mathrm{MS}$ of three most abundant ions with charge state 2 to 4 in each cycle, $60 \mathrm{~s}$ dynamic exclusion with a mass tolerance of 100.000 ppm, using Analyst ${ }^{\oplus}$ QS 1.1 software (Applied Biosystems/MDS Sciex, Foster City, USA). The fragment intensity multiplier was set to 20 and maximum accumulation time was $3 \mathrm{~s}$. Spectra acquired were submitted for peak list generation by Mascot Distiller integrated into Analyst ${ }^{\oplus}$ QS 1.1 software (Applied Biosystems/MDS Sciex, Foster City, USA). The peptide tandem mass spectra were searched against the NCBI non-redundant protein database 20120722 (19256848 sequences; 6606790375 residues) using MASCOT search engine with a precursor mass tolerance of $0.2 \mathrm{Da}$ and a fragment ion mass tolerance of 0.2 Da. Peptides were considered identified if the Mascot score was over the $95 \%$ confidence limit based on the 'identity' score of each peptide. Mass lists in the form of Mascot Generic Files were used as input for Mascot MS/MS ion searches of the NCBInr database using the matrix science web server (www.matrixscience.com) [37]. The following settings were applied for the online database search: Database $=$ NCBInr; Taxonomy $=$ Musculus; Enzyme $=$ Trypsin (with a maximum of 2 missed cleavages); Fixed modifications $=$ Carbamidomethyl $(\mathrm{C})$; Variable modifications = Acetyl (Protein N-term) and Oxidation (M); Peptide tolerance $= \pm 100 \mathrm{ppm}$; Mass values $=\mathrm{MH}+($ monoisotopic). Only probability scores, $\mathrm{p}<0.05$, were considered.

\section{Statistical analysis}

The results for biochemical parameters were analysed using unpaired t-test (GraphPad software Inc., CA). Results were expressed as mean \pm standard deviation (SD). Differences were considered to be statistically significant if the associated $\mathrm{p}$ value was $<0.05$.

\section{Results and discussion}

\section{Proteomic profile}

The separation of proteins by 2D-PAGE resolved approximately 275 proteins that could be detected and quantified by automated matching using the specialized software Progenesis Samespots, version 3.1 (Non-linear Dynamics, Newcastle upon Tyne, UK) (Figure 1). A comparison of female mice fed with high and low $n-3$ PUFA diets revealed 59 spots that were different, with a fold difference in the range of 2-9 folds. Differentially expressed proteins in females fed high or low $n-3$ PUFA were grouped according to their metabolic functions in the following pathways: lipid metabolism, one-carbon metabolism, carbohydrate, citric acid cycle and protein synthesis.

\section{N-3 PUFA alters regucalcin and ApoA-I expression to regulate lipid metabolism}

Mice fed a high $n-3$ PUFA diet showed a lower expression of regucalcin compared to mice fed a low $n-3$ PUFA diet (Table 1). Regucalcin is mainly expressed in rodent liver, and higher expression of regucalcin is linked to metabolic disorders including diabetes and lipid metabolism [38,39]. Regucalcin has been found to play a multifunctional role in different tissues [40], and is primarily involved in the maintenance of intracellular $\mathrm{Ca}^{2+}$ homeostasis [39]. Regulation of calcium homeostasis is important in many metabolic pathways including glucose metabolism and diabetes [41,42]. There are evidences linking higher expression of regucalcin to adipogenesis in adipocytes [43], and also alterations in lipid and glucose metabolism in vivo [44], which are predisposing factors to obesity and diabetes. Overexpression of regucalcin was also found to enhance glucose utilization and lipid production in the cloned rat hepatoma H4-II-E cells in vitro $[44,45]$. Concomitant with a decrease in regucalcin on a high $n-3$ PUFA diet was a significant decrease in plasma TG concentrations as compared to mice fed a low $n$ - 3 PUFA diet (Figure 2A). Although feeding a high $n-3$ PUFA diet had no significant effect on hepatic TG concentration, there was a trend towards a decrease compared to mice fed a low $n$-3 PUFA diet (Figure 2B). These findings suggest that the regulation of lipid metabolism by $n-3$ PUFA is likely mediated via regucalcin, which is a novel finding. We also observed a higher expression of Apolipoprotein A-I (ApoA-I) in mice fed the high $n$-3 PUFA diet. ApoA-I is the major protein component of HDL-c that mediates reverse cholesterol transport from extra-hepatic tissues to the liver for excretion [46]. It has been reported that $n-3$ PUFA supplementation alters lipoprotein containing proteome and suggests that this alteration will improve the functionality of HDL particle [47]. Increasing ApoA-I levels is an attractive strategy for the prevention of CVDs [3], thus a diet high in $n$-3 PUFA is likely inducing cardioprotective effects via increasing ApoA-I levels.

\section{$\mathrm{N}$-3 PUFA regulate proteins involved in one-carbon metabolism}

Mice fed a high $n$-3 PUFA diet showed a higher expression of S-adenosylmethionine synthase (SAM synthase) (Table 2) compared to mice fed a low $n-3$ PUFA diet. SAM synthase [48] catalyzes the synthesis of SAM from methionine and is responsible for regeneration of methionine from homocysteine (Hcy) [49]. Elevated plasma total Hcy levels are a fairly well established risk factor for CVD [50]. A high-fat diet was found to increase plasma Hcy levels in C57BL/6 mice [51], whereas $n$-3 PUFA was negatively associated with plasma Hcy [52]. A metaanalysis study also showed that the high consumption of n-3 PUFA decreases plasma Hcy [53]. Our study revealed 


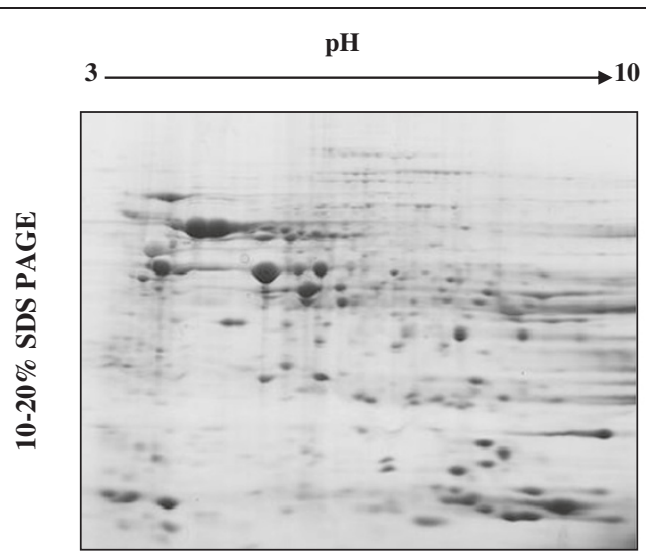

High $n$-3 PUFA

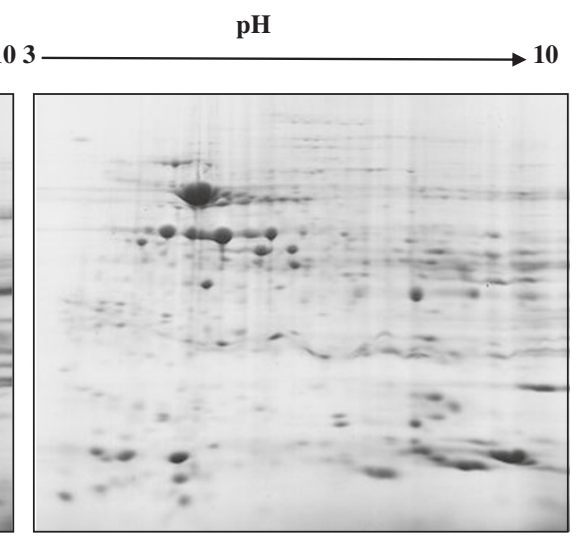

Low $n$-3 PUFA

Figure 1 2D-PAGE image of whole hepatic proteome of mice fed high or low $\boldsymbol{n}-\mathbf{3}$ polyunsaturated fatty acid enriched diets. The images represent scanned Coommasie stained gels of female C57BL/6 mice. Proteins were separated in the first dimension using immobilized pH 3-10 strips and then separated by mass using 10 to 20\% polyacrylamide gradient gels. Over 275 spots were resolved and detected using Progenesis Samespots, version 3.1.

that increased SAM synthase in mice fed high $n$-3 PUFA diet could be responsible for lowering Hcy levels.

In addition to increasing the expression of SAM synthase, a diet high in $n-3$ PUFA caused a decrease in adenosine kinase (ADK) protein expression compared to mice fed a low $n$-3 PUFA diet. ADK plays an important role in regulating the intracellular as well as extracellular concentrations of adenosine by catalyzing the phosphorylation of adenosine to AMP through the use of ATP [54]. ADK is highly expressed in the liver [55], and has been shown to play an important role in methyltransferase reactions to control SAM and Hcy levels [56]. A recent study has reported that inhibition of ADK promotes rodent and porcine islet beta-cell replication, and the authors have proposed ADK inhibition as a strategy for the treatment of diabetes [57]. Thus inhibition of ADK by $n-3$ PUFA could be a potential dietary based therapeutic strategy under diabetic conditions. We did not find a significant effect of the diets on plasma glucose levels (Figure 2C), however the levels of NEFA were significantly lower in animals fed a high $n-3$ PUFA diet
(Figure 2D), supporting insulin sensitizing effects of $n-3$ PUFA.

\section{Effect of $n-3$ PUFA on the regulation of carbohydrate metabolism}

$N-3$ PUFA have also been shown to increase insulin sensitivity [58] via regulating proteins involved in carbohydrate metabolism [59]. We observed a higher expression of hepatic fructose-1, 6-bisphosphatase (FBPase) and ketohexokinase (KHK) in mice fed a high $n$-3 PUFA diet (Table 1). FBPase converts fructose-1, 6-bisphophate to fructose-6-phosphate and is considered a key regulatory enzyme in gluconeogenesis [60]. A diet rich in $n$-3 PUFA was previously shown to increase FBPase expression in liver of 3 day old rat pups [61]. Fructose-6-phosphate is metabolised to glucose-6-phosphate thereby acting as a substrate for pentose phosphate pathway (PPP) [62]. We observed that mice fed a high $n$-3 PUFA diet had higher expression of 6-phosphogluconolactonase (6PGL) compared to mice fed the low $n-3$ PUFA diet (Table 1). 6PGL catalyzes the second step in the PPP [63], which is a major

Table 1 Hepatic proteins identified via peptide mapping and MS/MS fragmentation in C57BL/6 mice fed a diet high or low in $n-3$ polyunsaturated fatty acids

\begin{tabular}{lcccccc}
\hline Protein & GI & Mass & Score & Matches & Sequences & Metabolic pathway \\
\hline Fructose-1,6-biphosphatase & 51036635 & 40040 & 463 & $6(6)$ & $6(6)$ & Gluconeogenesis \\
Ketohexokinase & 31982229 & 33290 & 348 & $5(4)$ & $5(4)$ & \\
Apolipoprotein A-I & 109571 & 30358 & 295 & $7(2)$ & $7(2)$ & Lipid transport and metabolism \\
Cytosolic malate dehydrogenase & 387129 & 36625 & 238 & $4(4)$ & $4(4)$ & Citric acid cycle \\
GTP-specific succinyl COA synthase beta subunit & 3766203 & 44115 & 393 & $7(5)$ & $7(5)$ & Citric acid cycle \\
6-phosphogluconolactonase & 13384778 & 27465 & 501 & $10(6)$ & $10(6)$ & Pentose phosphate pathway \\
Regucalcin & 6677739 & 33899 & 90 & $2(1)$ & $2(1)$ & Regulatory protein \\
\hline
\end{tabular}

Gl=GenBank sequence identification number. 

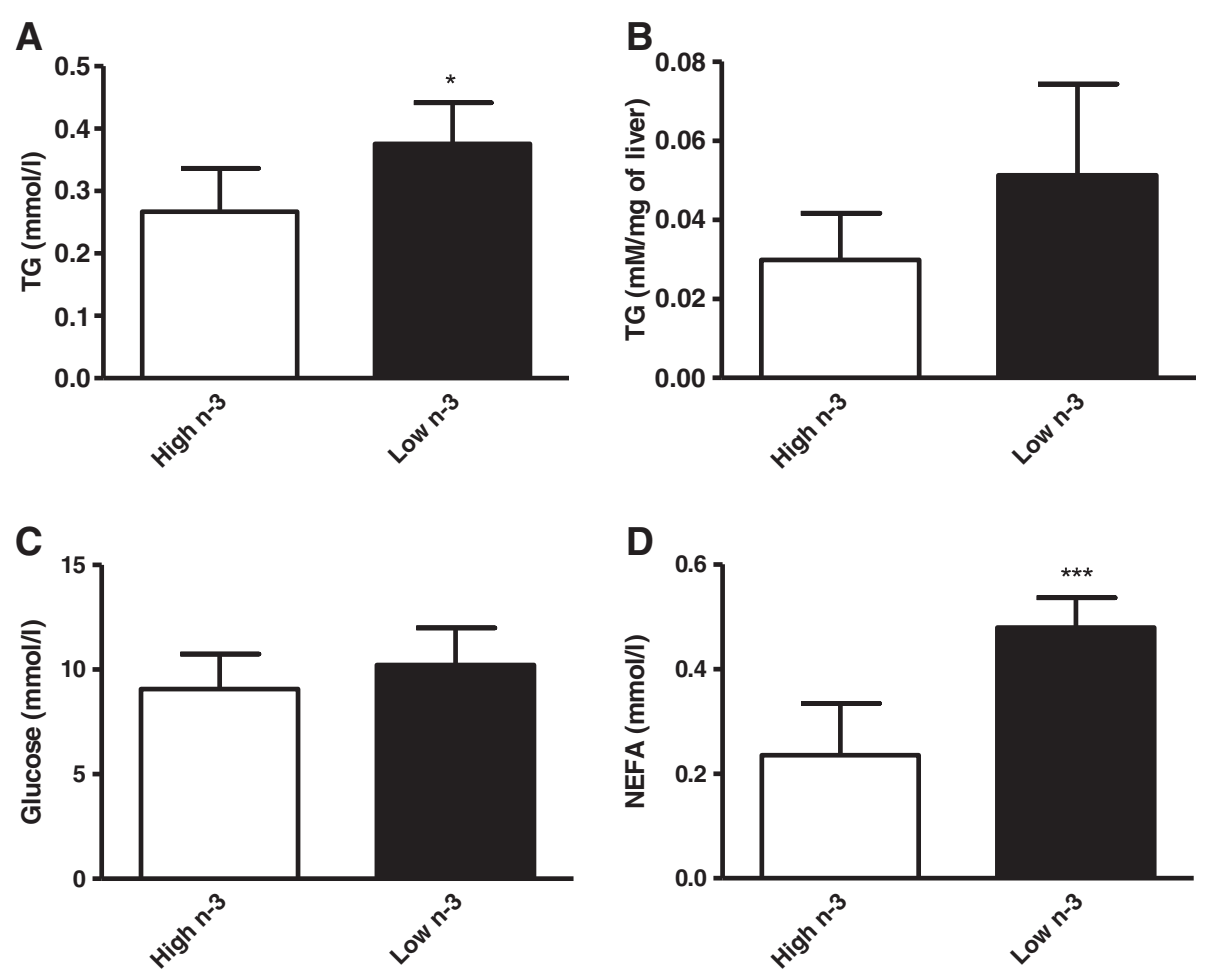

Figure 2 Biochemical parameters of female mice fed high or low $\boldsymbol{n}$-3 polyunsaturated fatty acid enriched diets. Concentrations of plasma triacylglycerol (TG) (A), hepatic TG (B), plasma glucose (C), and plasma non-esterified fatty acids (NEFA) (D) were measured as described in the methods section. Values are expressed as means $\pm \mathrm{SD}(\mathrm{n}=8)$, and P-value was calculated using unpaired t-test. ${ }^{*} \mathrm{P}<0.05$, ${ }^{* * *} \mathrm{P}<0.0001$.

source of NADPH and pentose sugars necessary for oxidative stress defence and nucleotide synthesis [64]. There are two distinct phases in this pathway; the first is the oxidative phase, which generates NADPH, and the second phase is the non-oxidative synthesis of 5-carbon sugar [65]. NADPH that results from the PPP is mainly used in reductive biosynthesis reactions within cells through increasing glutathione reductase, which is necessary to regenerate glutathione [64]. Both epidemiological and animal studies have also shown that high fructose predisposes to type-II diabetes and metabolic syndrome [66-68]. We found that mice fed a high $n-3$ PUFA diet had higher expression of KHK, which initiates the pathway to metabolize dietary fructose [69]. N-3 PUFA has previously been reported to have beneficial effects under fructose induced diabetic conditions [70]. This is the first report that provides evidence for $n$-3 PUFA mediated increase in fructose metabolism, likely due to an increase in the protein expression of KHK.

Table 2 Fold differences in abundance of hepatic proteins identified by LC-MS/MS in C57BL/6 mice fed a diet high or low in $n-3$ polyunsaturated fatty acids

\begin{tabular}{|c|c|c|c|c|c|c|c|}
\hline \#Protein & Function & High $n$-3 PUFA & Low $n-3$ PUFA & GI & Mass & Score & Matches \\
\hline Ornithine aminotransferase & Nitrogen homeostasis & $28.25 \uparrow$ & & 8393866 & 48723 & 60 & $2(1)$ \\
\hline S-adenosylmethionine synthase & One-carbon metabolism & $1.88 \uparrow$ & & 19526790 & 44051 & 503 & $11(8)$ \\
\hline Disulfide isomerase-A3 & Protein folding & $9.18 \uparrow$ & & 351707448 & 57366 & 81 & $2(1)$ \\
\hline Aldehyde dehydrogenase & Energy production & & $1.43 \uparrow$ & 560645 & 56686 & 55 & $1(1)$ \\
\hline Adenosine kinase & Phosphorylation & & $1.66 \uparrow$ & 19527306 & 40466 & 379 & $12(2)$ \\
\hline Lactoylglutathione lyase & Detoxification & $1.69 \uparrow$ & & 165932331 & 20967 & 278 & $7(6)$ \\
\hline
\end{tabular}

The images of the total protein pattern of 2D-gels were captured by video imaging using the ImageScanner III (LabScan 6.0 software, GE Healthcare, Life Sciences, Sweden). Progenesis Samespots, version 3.1, a specialized software (Non-linear Dynamics, Newcastle upon Tyne, UK) was then used to align and quantify the protein spots from the captured 2D-gel images. PUFA, polyunsaturated fatty acids; Gl, GenBank sequence identification number; $\uparrow=$ upregulation. 


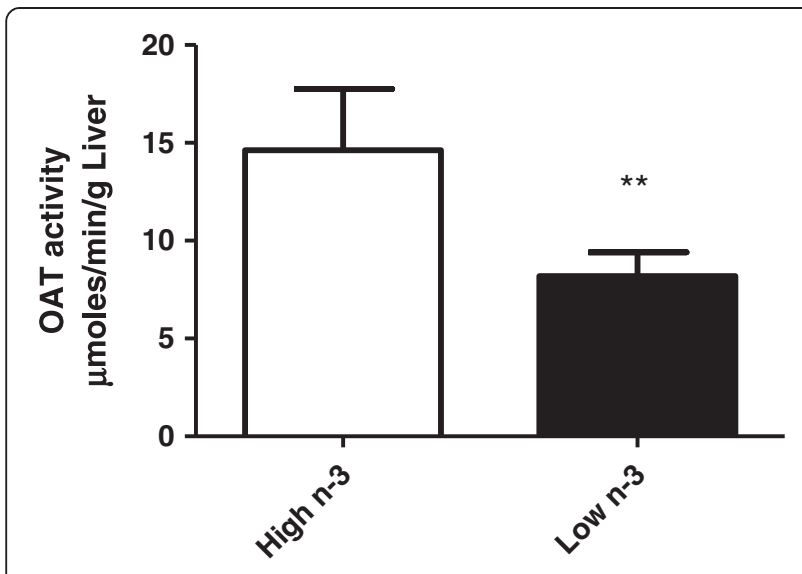

Figure 3 The effect of high and low $n-3$ polyunsaturated fatty acid enriched diets on hepatic ornithine aminotransferase (OAT) enzyme activity. The OAT enzyme activity was measured according to details given under the methods section. The enzyme activity was expressed as $\mu \mathrm{mol} / \mathrm{min} / \mathrm{g}$ liver; values are mean \pm SD ( $n=4$ per treatment).

Effect of $n-3$ PUFA on proteins involved in citric acid cycle Mice fed a high n-3 PUFA diet showed higher protein expression of cytosolic malate dehydrogenase $(\mathrm{MDH})$ and GTP specific succinyl CoA synthase (SCS) beta subunit compared to mice fed a low $n-3$ PUFA diet (Table 1 ). $\mathrm{MDH}$ is an enzyme that reversibly catalyzes the oxidation of malate to oxaloacetate using the reduction of NAD + to $\mathrm{NADH}$ [71], and is also involved in gluconeogenesis. N-3 PUFA was previously found to regulate the metabolic function of liver effectively by increasing $\mathrm{MDH}$ enzyme activity of rat liver $[59,72]$. SCS catalyzes the reversible reaction of succinyl-CoA to succinate, and is the only mitochondrial enzyme capable of ATP production via substrate level phosphorylation in the absence of oxygen [73]. SCS plays a key role in the citric acid cycle, ketone metabolism and heme synthesis [74]. Upregulation of $\mathrm{MDH}$ and SCS in the high $n-3$ PUFA diet group would result in an increase in oxaloacetate levels which has several possible fates: 1) transamination to aspartate, 2) conversion into glucose by the gluconeogenic pathway, 3) condensation with acetyl CoA to form citrate, or 4) conversion into pyruvate. Moreover, the animals fed a high $n$-3 PUFA diet revealed a dramatic increase in the expression of OAT compared to mice fed a low $n$ - 3 PUFA diet. We measured OAT enzyme activity to confirm the effect of dietary $n-3$ PUFA and observed a significant increase $(\mathrm{p}=0.0086)$ in OAT enzyme activity in animals fed a high $n-3$ PUFA diet compared to animals fed the low $n-3$ PUFA diet (Figure 3 ). This is the first study to report that $n-3$ PUFA enriched diets significantly increased OAT protein expression and enzyme activity. OAT is a pyridoxal-50-phosphate-dependent mitochondrial matrix aminotransferase that catalyses the inter-conversion of ornithine into glutamate semialdehyde [75]. OAT is located at a crossing between two important metabolisms: arginine and polyamine metabolism on one side and glutamate and proline metabolism on the other side [76]. OAT is mainly found in the liver where its response to hormones and variations in dietary protein intake is subject to complex regulatory mechanisms $[27,77,78]$. OAT plays a role in the adaptation to the level of protein supply, and also to the regulation of the availability of arginine and glutamine. Glutamine has a number of important regulatory roles in increasing protein synthesis, decreasing protein degradation, and also regulating arginine functions (i.e. stimulating the release of growth hormones, insulin-like growth factor 1, insulin

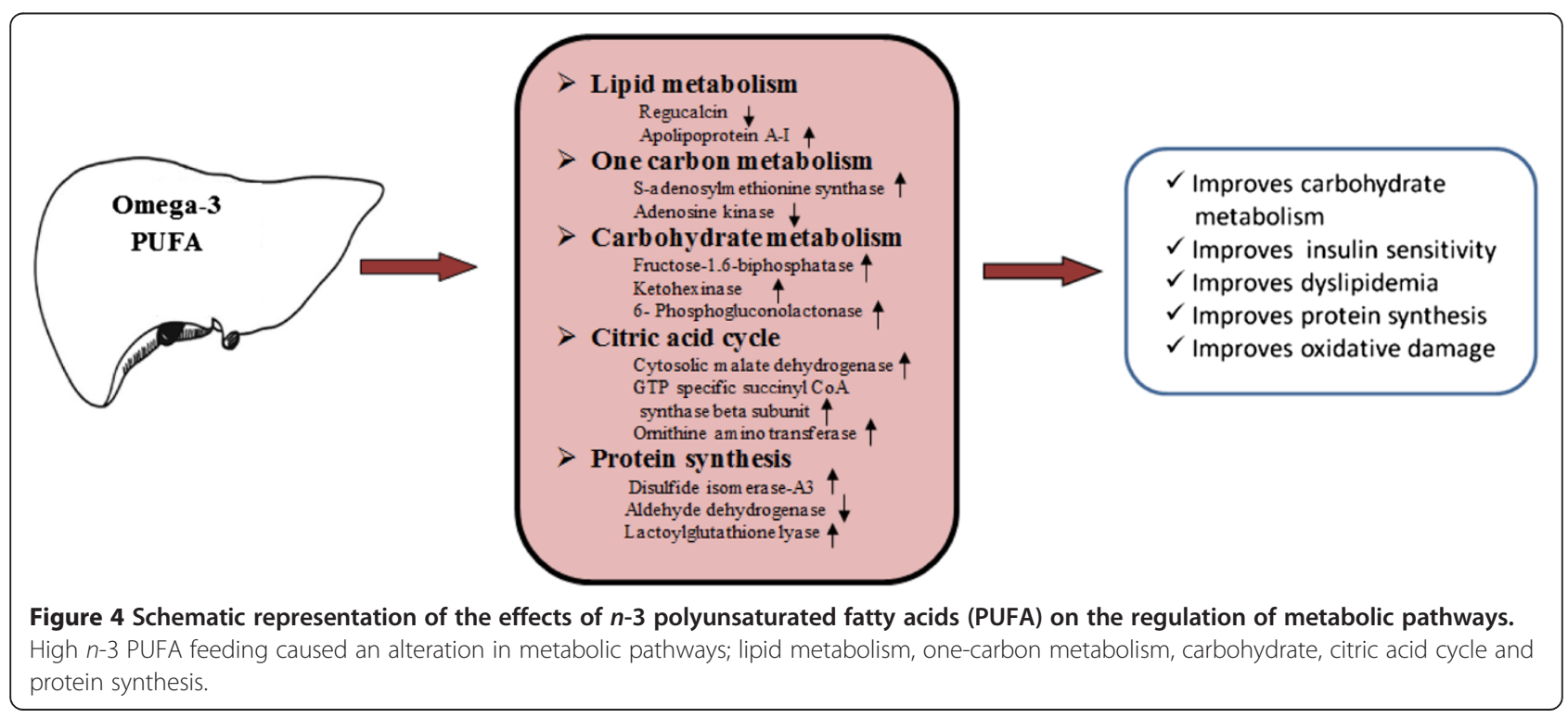


and prolactin) [79]. Thus, an overexpression of OAT could lead to changes in protein metabolism, thereby decreasing insulin resistance in type II diabetes. To the best of our knowledge, this is the first study that establishes an association between $n$-3 PUFA and hepatic OAT expression. Taken together, high $n$-3 PUFA diet appears to regulate carbohydrate metabolism through alteration of many functional proteins such as FBPase, KHK, MDH, SCS and OAT.

\section{Effect of $n-3$ PUFA on the regulation of protein synthesis}

Animals fed a diet high in $n-3$ PUFA revealed an increase in protein disulfide isomerase-A3 (PDI-A3) expression compared to mice fed a low $n$-3 PUFA diet. PDI-A3 constitutes a family of structurally related enzymes that catalyze disulfide bond formation, reduction, or isomerization of newly synthesized proteins in the lumen of the endoplasmic reticulum [80]. It has both a disulfide isomerase activity that helps the correct formation of disulfide bridges between cysteine residues and a chaperone activity preventing proteins from misfolding in the endoplasmic reticulum [81]. A reduction in PDIA3 activity is associated with impaired liver function [82]. Previously, it has been reported that diets enriched in menhaden oil increased activation (phosphorylation) of anabolic signaling proteins in muscle during administration of insulin and amino acids [83], and also increased the non-oxidative whole-body disposal of amino acids [83,84]. N-3 PUFA derived resolvins and protectins also prevent liver DNA damage and oxidative stress [85]; thus, significantly decreasing inflammatory liver injury and hepatic steatosis [86,87]. Our findings suggest that diets enriched in $n-3$ PUFA increase protein synthesis through inducing the expression of disulfide isomerase-A3.

We also observed a lower expression of aldehyde dehydrogenase (ALDH) in mice fed the high $n$-3 PUFA diet compared to mice fed the low $n-3$ PUFA diet (Table 2). ALDHs are the products of a large gene family and catalyze irreversible oxidation of a variety of biological aldehydes including products of lipid peroxidation [88]. Increased levels of ALDH are indicative of oxidative stress [89]. The $n$-3 PUFAs were shown to decrease oxidative stress $[90,91]$, and also to reduce the vascular-derived oxidative stress associated with diabetes [92], which are likely mediated via inhibition of ALDHs. These findings were further supported by increased expression of lactoylglutathione lyase (glyoxalase 1 ) in mice fed a high $n$-3 PUFA diet (Table 2). Glyoxalase 1 is critical for the detoxification of reactive dicarbonyls, such as methylglyoxal [93]. These reactive dicarbonyls are potent precursors of advanced glycation end products (AGEs), well known to be increased under diabetic conditions [94,95]. An increased expression of glyoxalase 1 in high $n$-3 PUFA diet would therefore cause a reduction in AGE production, thereby eliciting beneficial health effects under diabetic conditions.

\section{Conclusions}

In conclusion, our data suggests an important functional role of dietary $n-3$ PUFA in regulating proteins involved in lipids, glucose metabolism and protein synthesis as illustrated in Figure 4. We are reporting for the first time that $n$-3 PUFA down-regulates the expression of regucalcin, a potent player in lipid metabolism disorders. Furthermore, we have been able to demonstrate a novel involvement of n-3 PUFA in the regulation of proteins involved in one-carbon metabolism (SAM synthase and ADK), carbohydrate metabolism (FBPase, KHK and 6PGL), citric acid cycle (MDH, SCS and OAT), and protein synthesis (PDI-A3, ALDH and glyoxalase-1). Our findings have laid the foundation to undertake further studies to elucidate the potential health benefits of regulating the identified proteins and their pathways as a therapeutic strategy.

\section{Abbreviations}

ADK: Adenosine kinase; AGEs: Advanced glycation end products; ALDH: Aldehyde dehydrogenase; CVDs: Cardiovascular diseases; DHB: 2,5-Dihydroxybenzoic acid; DTT: Dithiothreitol; FA: Formic acid;

FBPase: Fructose-1, 6-bisphosphatase; GaP: Memorial University Genomics and Proteomics; GLC: Gas-liquid chromatography; Hcy: Homocysteine; IEF: Isoelectric focusing; IPG: Immobilized pH gradient; LC-MS/MS: Liquid chromatography-tandem mass spectrometry; MALDI TOF MS: Matrix assisted laser desorption/ionization time-of-flight mass spectrometry; MDH: Malate dehydrogenase; MUFA: Monounsaturated fatty acids; N-3 PUFA: Omega-3 polyunsaturated fatty acids; NEFA: Non-esterified fatty acids; $\mathrm{NH}_{4} \mathrm{HCO} /$ CAN: Ammonium bicarbonate/acetonitrile; OAT: Ornithine Aminotransferase; PDI-A3: Protein disulfide isomerase-A3; PPP: Pentose phosphate pathway; 6PGL: 6-Phosphogluconolactonase; SAM: S-adenosylmethionine synthase; SCS: Succinyl COA synthase; SD: Standard deviation; SDS: Sodium dodecyl sulfate; SFA: Saturated fatty acids; TFA: Trifluoroacetic acid; TG: Triglyceride; 2D-PAGE: Two dimensional polyacrylamide gel electrophoresis.

Competing interests

The authors declare that they have no competing financial, professional or personal interests that might have influenced the performance or presentation of the work described in this manuscript.

\section{Authors' contributions}

AA conducted the 2D-PAGE experiments, in gel digestion of gel spots, analyzed and interpreted data, and drafted the manuscript; KB undertook the animal study, carried out the biochemical parameters, interpreted data and participated in manuscript preparation; NB provided open access to instrumentation needed for proteomics experiment and participated in final revisions, SKC conceived the study, initiated the experimental design, coordinated the study, interpreted data, and drafted the manuscript. All authors read and approved the final manuscript.

\section{Acknowledgements}

Authors would like to thank the Natural Sciences and Engineering Research Council of Canada (NSERC) and the Canadian Institutes of Health Research (CIHR) for providing financial support. Infrastructure was supported by the Canada Foundation for Innovation (CFI) New Opportunities Fund. We would like to acknowledge Dr. John T. Brosnan and Patrick McNicholas for performing the OAT enzyme activity. We would also like to thank Jungie Hu for providing laboratory assistance with proteomics studies. 


\section{Author details}

${ }^{1}$ Department of Biochemistry, Memorial University of Newfoundland, St. John's, NL, A1B 3X9, Canada. ²Department of Biology, Memorial University of Newfoundland, St. John's, NL, Canada. ${ }^{3}$ Current address: Agriculture and AgriFood Canada, Winnipeg, MB, Canada

Received: 9 December 2013 Accepted: 15 January 2014

Published: 17 January 2014

\section{References}

1. Mutch DM, Wahli W, Williamson G: Nutrigenomics and nutrigenetics: the emerging faces of nutrition. FASEB J 2005, 19:1602-1616.

2. Apte SA, Cavazos DA, Whelan KA, Degraffenried LA: A low dietary ratio of omega- 6 to omega-3 Fatty acids may delay progression of prostate cancer. Nutr Cancer 2013, 65:556-562.

3. Miles RR, Perry W, Haas JV, Mosior MK, N'Cho M, Wang JW, Yu P, Calley J, Yue Y, Carter Q, et al: Genome-wide screen for modulation of hepatic apolipoprotein A-I (ApoA-I) secretion. J Biol Chem 2013, 288:6386-6396.

4. Joffe $Y T$, Collins M, Goedecke JH: The relationship between dietary fatty acids and inflammatory genes on the obese phenotype and serum lipids. Nutrients 2013, 5:1672-1705.

5. Lands B: A critique of paradoxes in current advice on dietary lipids. Prog Lipid Res 2008, 47:77-106.

6. Alvheim AR, Malde MK, Osei-Hyiaman D, Lin YH, Pawlosky RJ, Madsen L, Kristiansen K, Froyland L, Hibbeln JR: Dietary linoleic acid elevates endogenous 2-AG and anandamide and induces obesity. Obesity 2012, 20:1984-1994

7. Gonzalez-Periz A, Horrillo R, Ferre N, Gronert K, Dong B, Moran-Salvador E, Titos E, Martinez-Clemente M, Lopez-Parra M, Arroyo V, Claria J: Obesityinduced insulin resistance and hepatic steatosis are alleviated by omega-3 fatty acids: a role for resolvins and protectins. FASEB J 2009, 23:1946-1957.

8. Serhan CN, Hong S, Gronert K, Colgan SP, Devchand PR, Mirick G, Moussignac RL: Resolvins: a family of bioactive products of omega-3 fatty acid transformation circuits initiated by aspirin treatment that counter proinflammation signals. J Exp Med 2002, 196:1025-1037.

9. Harris WS, Bulchandani D: Why do omega-3 fatty acids lower serum triglycerides? Curr Opin Lipidol 2006, 17:387-393.

10. Reiffel JA, McDonald A: Antiarrhythmic effects of omega-3 fatty acids. Am J Cardiol 2006, 98:50i-60i.

11. Maroon JC, Bost JW: Omega-3 fatty acids (fish oil) as an antiinflammatory: an alternative to nonsteroidal anti-inflammatory drugs for discogenic pain. Surg Neurol 2006, 65:326-331.

12. Harris WS, Isley WL: Clinical trial evidence for the cardioprotective effects of omega-3 fatty acids. Curr Atheroscler Rep 2001, 3:174-179.

13. Marchioli R, Silletta MG, Levantesi G, Pioggiarella R: Omega-3 fatty acids and heart failure. Curr Atheroscler Rep 2009, 11:440-447.

14. Lavie CJ, Milani RV, Mehra MR, Ventura HO: Omega-3 polyunsaturated fatty acids and cardiovascular diseases. J Am Coll Cardiol 2009, 54:585-594.

15. Kris-Etherton PM, Harris WS, Appel $\sqcup$, Nutrition C: Fish consumption, fish oil, omega-3 fatty acids, and cardiovascular disease. Arterioscler Thromb Vasc Biol 2003, 23:e20-e30.

16. Kuda O, Jelenik T, Jilkova Z, Flachs P, Rossmeisl M, Hensler M, Kazdova L, Ogston N, Baranowski M, Gorski J, et al: n-3 fatty acids and rosiglitazone improve insulin sensitivity through additive stimulatory effects on muscle glycogen synthesis in mice fed a high-fat diet. Diabetologia 2009, 52:941-951.

17. de Assis AM, Rech A, Longoni A, Rotta LN, Denardin CC, Pasquali MA, Souza DO, Perry ML, Moreira JC: Omega3-Polyunsaturated fatty acids prevent lipoperoxidation, modulate antioxidant enzymes, and reduce lipid content but do not alter glycogen metabolism in the livers of diabetic rats fed on a high fat thermolyzed diet. Mol Cell Biochem 2012, 361:151-160.

18. Simopoulos AP: The importance of the omega-6/omega-3 fatty acid ratio in cardiovascular disease and other chronic diseases. Exp Biol Med (Maywood) 2008, 233:674-688.

19. Calder PC: N-3 polyunsaturated fatty acids and inflammation: from molecular biology to the clinic. Lipids 2003, 38:343-352.

20. Massaro M, Scoditti E, Carluccio MA, De Caterina R: Basic mechanisms behind the effects of $\mathrm{n}-3$ fatty acids on cardiovascular disease. Prostaglandins Leukot Essent Fatty Acids 2008, 79:109-115.
21. Adkins $Y$, Kelley DS: Mechanisms underlying the cardioprotective effects of omega-3 polyunsaturated fatty acids. J Nutr Biochem 2010, 21:781-792.

22. Wada M, DeLong CJ, Hong YH, Rieke CJ, Song I, Sidhu RS, Yuan C, Warnock M, Schmaier AH, Yokoyama C, et al: Enzymes and receptors of prostaglandin pathways with arachidonic acid-derived versus eicosapentaenoic acid-derived substrates and products. J Biol Chem 2007, 282:22254-22266.

23. Schweigert FJ: Nutritional proteomics: methods and concepts for research in nutritional science. Ann Nutr Metab 2007, 51:99-107.

24. Bunger M, Hooiveld GJ, Kersten S, Muller M: Exploration of PPAR functions by microarray technology-a paradigm for nutrigenomics. Biochim Biophys Acta 2007, 1771:1046-1064.

25. Balogun KA, Albert CJ, Ford DA, Brown RJ, Cheema SK: Dietary omega-3 polyunsaturated Fatty acids alter the Fatty Acid composition of hepatic and plasma bioactive lipids in C57BL/6 mice: a lipidomic approach. PLoS One 2013, 8:e82399.

26. Chechi K, Cheema SK: Maternal diet rich in saturated fats has deleterious effects on plasma lipids of mice. Exp Clin Cardiol 2006, 11:129-135.

27. Herzfeld A, Knox WE: The properties, developmental formation, and estrogen induction of ornithine aminotransferase in rat tissues. $J$ Biol Chem 1968, 243:3327-3332.

28. Gornall AG, Bardawill CJ, David MM: Determination of serum proteins by means of the biuret reaction. J Biol Chem 1949, 177:751-766.

29. Bradford MM: A rapid and sensitive method for the quantitation of microgram quantities of protein utilizing the principle of protein-dye binding. Anal Biochem 1976, 72:248-254.

30. Wu HC, Chen TN, Kao SH, Shui HA, Chen WJ, Lin HJ, Chen HM: Isoelectric focusing management: an investigation for salt interference and an algorithm for optimization. J Proteome Res 2010, 9:5542-5556.

31. Laemmli UK: Cleavage of structural proteins during the assembly of the head of bacteriophage T4. Nature 1970, 227:680-685.

32. Fan Y, Murphy TB, Byrne JC, Brennan L, Fitzpatrick JM, Watson RW: Applying random forests to identify biomarker panels in serum 2D-DIGE data for the detection and staging of prostate cancer. J Proteome Res 2011, 10:1361-1373.

33. Shevchenko A, Tomas H, Havlis J, Olsen JV, Mann M: In-gel digestion for mass spectrometric characterization of proteins and proteomes. Nat Protoc 2006, 1:2856-2860.

34. Shevchenko A, Jensen ON, Podtelejnikov AV, Sagliocco F, Wilm M, Vorm O, Mortensen P, Shevchenko A, Boucherie H, Mann M: Linking genome and proteome by mass spectrometry: large-scale identification of yeast proteins from two dimensional gels. Proc Natl Acad Sci U S A 1996 93:14440-14445.

35. Thomas H, Havlis J, Peychl J, Shevchenko A: Dried-droplet probe preparation on AnchorChip targets for navigating the acquisition of matrix-assisted laser desorption/ionization time-of-flight spectra by fluorescence of matrix/analyte crystals. Rapid Commun Mass Spectrom: RCM 2004, 18:923-930

36. Keller BO, Sui J, Young AB, Whittal RM: Interferences and contaminants encountered in modern mass spectrometry. Anal Chim Acta 2008, 627:71-81.

37. Perkins DN, Pappin DJ, Creasy DM, Cottrell JS: Probability-based protein identification by searching sequence databases using mass spectrometry data. Electrophor 1999, 20:3551-3567.

38. Yamaguchi M: The role of regucalcin in nuclear regulation of regenerating liver. Biochem Biophys Res Commun 2000, 276:1-6.

39. Yamaguchi $M$ : Role of regucalcin in maintaining cell homeostasis and function (review). Int J Mol Med 2005, 15:371-389.

40. Yamaguchi M, Morooka Y, Misawa H, Tsurusaki Y, Nakajima R: Role of endogenous regucalcin in transgenic rats: suppression of kidney cortex cytosolic protein phosphatase activity and enhancement of heart muscle microsomal Ca2 + -ATPase activity. J Cell Biochem 2002, 86:520-529.

41. Kraus-Friedmann N, Feng L: The role of intracellular Ca2+ in the regulation of gluconeogenesis. Metab 1996, 45:389-403

42. Hamada Y, Nagasaki H, Fuchigami M, Furuta S, Seino Y, Nakamura J, Oiso Y: The alpha-glucosidase inhibitor miglitol affects bile acid metabolism and ameliorates obesity and insulin resistance in diabetic mice. Metab 2013, 62:734-742.

43. Yamaguchi M, Weitzmann MN, Baile CA, Murata T: Exogenous regucalcin suppresses osteoblastogenesis and stimulates adipogenesis in mouse bone marrow culture. Integr Biol (Camb) 2012, 4:1215-1222. 
44. Yamaguchi M: Regucalcin and metabolic disorders: osteoporosis and hyperlipidemia are induced in regucalcin transgenic rats. Mol Cell Biochem 2010, 341:119-133.

45. Yamaguchi M, Murata T: Involvement of regucalcin in lipid metabolism and diabetes. Metabolism 2013, 62:1045-1051

46. Chiesa G, Sirtori CR: Apolipoprotein A-I (Milano): current perspectives. Curr Opin Lipidol 2003, 14:159-163.

47. Burillo E, Mateo-Gallego R, Cenarro A, Fiddyment S, Bea AM, Jorge I, Vazquez J, Civeira F: Beneficial effects of omega-3 fatty acids in the proteome of high-density lipoprotein proteome. Lipids Health Dis 2012, 11:116.

48. Sampath H, Ntambi JM: Polyunsaturated fatty acid regulation of genes of lipid metabolism. Annu Rev Nutr 2005, 25:317-340.

49. Mato JM, Alvarez L, Ortiz P, Pajares MA: S-adenosylmethionine synthesis: molecular mechanisms and clinical implications. Pharmacol Ther 1997, 73:265-280.

50. Kerins DM, Koury MJ, Capdevila A, Rana S, Wagner C: Plasma S adenosylhomocysteine is a more sensitive indicator of cardiovascular disease than plasma homocysteine. Am J Clin Nutr 2001, 74:723-729.

51. Yun KU, Ryu CS, Oh JM, Kim CH, Lee KS, Lee CH, Lee HS, Kim BH, Kim SK: Plasma homocysteine level and hepatic sulfur amino acid metabolism in mice fed a high-fat diet. Eur J Nutr 2013, 52:127-134.

52. Mehmetoglu I, Yerlikaya FH, Kurban S, Polat H: Plasma omega-3 fatty acid levels negatively and omega- 6 fatty acid levels positively associated with other cardiovascular risk factors including homocysteine in severe obese subjects. Asia Pac J Clin Nutr 2012, 21:519-525.

53. Huang $T$, Wahlqvist ML, Li D: Effect of $n-3$ polyunsaturated fatty acid on gene expression of the critical enzymes involved in homocysteine metabolism. Nutr J 2012, 11:6.

54. Park J, Gupta RS: Adenosine kinase and ribokinase-the RK family of proteins. Cell Mol Life Sci 2008, 65:2875-2896.

55. Andres CM, Palella TD, Fox IH: Human placental adenosine kinase: purification and characterization. Adv Exp Med Biol 1979, 122B:41-43.

56. Bjursell MK, Blom HJ, Cayuela JA, Engvall ML, Lesko N, Balasubramaniam S, Brandberg G, Halldin M, Falkenberg M, Jakobs C, et al: Adenosine kinase deficiency disrupts the methionine cycle and causes hypermethioninemia, encephalopathy, and abnormal liver function. Am J Hum Genet 2011, 89:507-515.

57. Annes JP, Ryu JH, Lam K, Carolan PJ, Utz K, Hollister-Lock J, Arvanites AC, Rubin LL, Weir G, Melton DA: Adenosine kinase inhibition selectively promotes rodent and porcine islet beta-cell replication. Proc Natl Acad SCl USA 2012, 109:3915-3920.

58. Hartweg J, Perera R, Montori V, Dinneen S, Neil HA, Farmer A: Omega-3 polyunsaturated fatty acids (PUFA) for type 2 diabetes mellitus. Cochrane Database Syst Rev 2008. Issue 1. Art. No.CD003205. doi:10.1002/14651858. CD003205.pub2

59. Yilmaz HR, Songur A, Ozyurt B, Zararsiz I, Sarsilmaz M: The effects of $n-3$ polyunsaturated fatty acids by gavage on some metabolic enzymes of rat liver. Prostaglandins Leukot Essent Fatty Acids 2004, 71:131-135.

60. Marcus F, Rittenhouse J, Gontero B, Harrsch PB: Function, structure and evolution of fructose-1,6-bisphosphatase. Arch Biol Med Exp (Santiago) 1987, 20:371-378.

61. Novak EM, Lee EK, Innis SM, Keller BO: Identification of novel protein targets regulated by maternal dietary fatty acid composition in neonatal rat liver. J Proteomics 2009, 73:41-49.

62. Manganelli G, Masullo U, Passarelli S, Filosa S: Glucose-6-phosphate dehydrogenase deficiency: disadvantages and possible benefits. Cardiovasc Hematol Disord Drug Targets 2013, 13:73-82.

63. Collard F, Collet JF, Gerin I, Veiga-da-Cunha M, Van Schaftingen E: Identification of the CDNA encoding human 6-phosphogluconolactonase, the enzyme catalyzing the second step of the pentose phosphate pathway (1). FEBS Lett 1999, 459:223-226.

64. Dashty M: A quick look at biochemistry: carbohydrate metabolism. Clin Biochem 2013, 46:1339-1352.

65. Kruger NJ, von Schaewen A: The oxidative pentose phosphate pathway: structure and organisation. Curr Opin Plant Biol 2003, 6:236-246.

66. Basciano $H$, Federico L, Adeli K: Fructose, insulin resistance, and metabolic dyslipidemia. Nutr Metab 2005, 2:5.

67. Johnson RJ, Segal MS, Sautin Y, Nakagawa T, Feig DI, Kang DH, Gersch MS, Benner S, Sanchez-Lozada LG: Potential role of sugar (fructose) in the epidemic of hypertension, obesity and the metabolic syndrome, diabetes, kidney disease, and cardiovascular disease. Am J Clin Nutr 2007, 86:899-906.
68. Miller A, Adeli K: Dietary fructose and the metabolic syndrome. Curr Opin Gastroenterol 2008, 24:204-209.

69. Raushel FM, Cleland WW: Bovine liver fructokinase: purification and kinetic properties. Biochem 1977, 16:2169-2175.

70. Karsenty J, Landrier JF, Rousseau-Ralliard D, Robbez-Masson V, Margotat A, Deprez P, Lechene P, Grynberg A, Lairon D, Planells R, Gastaldi M: Beneficial effects of omega-3 fatty acids on the consequences of a fructose diet are not mediated by PPAR delta or PGC1 alpha. Eur J Nutr 2013, 52:1865-1874.

71. Musrati RA, Kollarova M, Mernik N, Mikulasova D: Malate dehydrogenase: distribution, function and properties. Gen Physiol Biophys 1998, 17:193-210.

72. Khan MW, Priyamvada S, Khan SA, Khan S, Naqshbandi A, Yusufi AN: Protective effect of omega-3 polyunsaturated fatty acids (PUFAs) on sodium nitroprusside-induced nephrotoxicity and oxidative damage in rat kidney. Hum Exp Toxicol 2012, 31:1035-1049.

73. Nishimura JS: Succinyl-CoA synthetase structure-function relationships and other considerations. Adv Enzymol Relat Areas Mol Biol 1986, 58:141-172.

74. Phillips D, Aponte AM, French SA, Chess DJ, Balaban RS: Succinyl-CoA synthetase is a phosphate target for the activation of mitochondrial metabolism. Biochemistry 2009, 48:7140-7149.

75. Ventura G, De Bandt JP, Segaud F, Perret C, Robic D, Levillain O, Le Plenier S, Godard C, Cynober L, Moinard C: Overexpression of ornithine aminotransferase: consequences on amino acid homeostasis. $\mathrm{Br} J$ Nutr 2009, 101:843-851.

76. Marsman HA, Heger M, Kloek JJ, Nienhuis SL, ten Kate FJ, van Gulik TM: Omega-3 fatty acids reduce hepatic steatosis and consequently attenuate ischemia-reperfusion injury following partial hepatectomy in rats. Dig Liver Dis 2011, 43:984-990.

77. Boon L, Geerts WJ, Jonker A, Lamers WH, Van Noorden CJ: High protein diet induces pericentral glutamate dehydrogenase and ornithine aminotransferase to provide sufficient glutamate for pericentral detoxification of ammonia in rat liver lobules. Histochem Cell Biol 1999, 111:445-452.

78. O'Sullivan D, Brosnan JT, Brosnan ME: Catabolism of arginine and ornithine in the perfused rat liver: effect of dietary protein and of glucagon. Am J Physiol Endocrinol Metab 2000, 278:E516-E521.

79. Smith RJ: Glutamine metabolism and its physiologic importance. JPEN J Parenter Enteral Nutr 1990, 14:40S-44S

80. Turano C, Coppari S, Altieri F, Ferraro A: Proteins of the PDI family: unpredicted non-ER locations and functions. J Cell Physiol 2002, 193:154-163.

81. Hatahet F, Ruddock LW: Substrate recognition by the protein disulfide isomerases. FEBS J 2007, 274:5223-5234.

82. Cordeiro OD, Silva TS, Alves RN, Costas B, Wulff T, Richard N, de Vareilles M, Conceicao LE, Rodrigues PM: Changes in liver proteome expression of Senegalese sole (Solea senegalensis) in response to repeated handling stress. Mar Biotechnol (NY) 2012, 14:714-729.

83. Gingras AA, White PJ, Chouinard PY, Julien P, Davis TA, Dombrowski L, Couture $Y$, Dubreuil P, Myre A, Bergeron K, et al: Long-chain omega-3 fatty acids regulate bovine whole-body protein metabolism by promoting muscle insulin signalling to the Akt-mTOR-S6K1 pathway and insulin sensitivity. J Physiol 2007, 579:269-284.

84. Smith Gl, Atherton P, Reeds DN, Mohammed BS, Rankin D, Rennie MJ, Mittendorfer B: Dietary omega-3 fatty acid supplementation increases the rate of muscle protein synthesis in older adults: a randomized controlled trial. Am J Clin Nutr 2011, 93:402-412.

85. Iwasaki W, Kume M, Kudo K, Uchinami H, Kikuchi I, Nakagawa Y, Yoshioka M, Yamamoto $Y$ : Changes in the fatty acid composition of the liver with the administration of $\mathrm{N}-3$ polyunsaturated fatty acids and the effects on warm ischemia/reperfusion injury in the rat liver. Shock 2010, 33:306-314.

86. Zuniga J, Venegas F, Villarreal M, Nunez D, Chandia M, Valenzuela R, Tapia G, Varela P, Videla LA, Fernandez V: Protection against in vivo liver ischemia-reperfusion injury by $n-3$ long-chain polyunsaturated fatty acids in the rat. Free Radic Res 2010, 44:854-863.

87. Yamaguchi M: Role of regucalcin in calcium signaling. Life Sci 2000, 66:1769-1780

88. Hjelle JJ, Petersen DR: Hepatic aldehyde dehydrogenases and lipid peroxidation. Pharmacol Biochem Behav 1983, 18(Suppl 1):155-160.

89. Liao J, Sun A, Xie Y, Isse T, Kawamoto T, Zou Y, Ge J: Aldehyde dehydrogenase-2 deficiency aggravates cardiac dysfunction elicited by endoplasmic reticulum stress induction. Mol Med 2012, 18:785-793. 
90. Nalsen C, Vessby B, Berglund L, Uusitupa M, Hermansen K, Riccardi G, Rivellese A, Storlien L, Erkkila A, Yla-Herttuala S, et al: Dietary (n-3) fatty acids reduce plasma F2-isoprostanes but not prostaglandin F2alpha in healthy humans. J Nutr 2006, 136:1222-1228.

91. Mori TA, Dunstan DW, Burke V, Croft KD, Rivera JH, Beilin LJ, Puddey IB: Effect of dietary fish and exercise training on urinary F2-isoprostane excretion in non-insulin-dependent diabetic patients. Metabolism 1999, 48:1402-1408.

92. McDonald DM, O'Kane F, McConville M, Devine AB, McVeigh GE: Platelet redox balance in diabetic patients with hypertension improved by $\mathrm{n}-3$ fatty acids. Diabetes Care 2013, 36:998-1005.

93. Kim KM, Kim YS, Jung DH, Lee J, Kim JS: Increased glyoxalase I levels inhibit accumulation of oxidative stress and an advanced glycation end product in mouse mesangial cells cultured in high glucose. Exp Cell Res 2012, 318:152-159.

94. Jack M, Wright D: Role of advanced glycation endproducts and glyoxalase I in diabetic peripheral sensory neuropathy. Transl Res 2012, 159:355-365.

95. Lee BH, Hsu WH, Hsu YW, Pan TM: Dimerumic acid attenuates receptor for advanced glycation endproducts signal to inhibit inflammation and diabetes mediated by Nrf2 activation and promotes methylglyoxal metabolism into d-lactic acid. Free Radic Biol Med 2013, 60:7-16.

doi:10.1186/1743-7075-11-6

Cite this article as: Ahmed et al: Novel regulatory roles of omega-3 fatty acids in metabolic pathways: a proteomics approach. Nutrition \& Metabolism 2014 11:6.

\section{Submit your next manuscript to BioMed Central and take full advantage of:}

- Convenient online submission

- Thorough peer review

- No space constraints or color figure charges

- Immediate publication on acceptance

- Inclusion in PubMed, CAS, Scopus and Google Scholar

- Research which is freely available for redistribution 